\title{
Quality of Life, Depression and Involvement in Physical Activity of Parents with Disabled Childrenin Greece \\ Calidad de vida, depresión y participación en actividad física de los padres deniños discapacitados en Grecia
}

\author{
EmmanouilKSkordilis \\ National and Kapodistrian University of Athens, Greece
}

\begin{abstract}
The study examined the quality of life (QoL) of parents with disabled children in Greece. Further, the relationship between QoL with depressive symptoms and involvement in physical activity were reported as well. The total sample constituted from 73 parents $($ Mean age $=42.87$ years, SD = 7.58), classified to 42 parents of children with disabilities and 31 parents of children without disabilities (control group). The participants responded to the Beck Depression Inventory II (BDI-II) (Beck, Steer \& Garbin, 1996), the QoL SF36v2 scale (Ware et al., 2007), and the Self Administered Physical Activity Checklist (SAPAC) (Sallis, Strikmiller, Harsha, \& Feldman, 1996). The multivariate (lambda $=.99, \mathrm{~F}=.35$, $\mathrm{p}=.70$, eta $^{2}=.01$ ) and univariate comparisons between the two parental groups did not reveal significant differences in the physical (PCS) and mental components (MCS) of the SF36v2. The QoL was significantly related to the depressive symptoms, while the involvement in physical activity was not related to QoL. On the other hand, parents of children with disabilities had less sedentary behaviors compared to the control group. The overall findings are discussed in line with relevant studies examining the QoL of families with disabled children.

Keywords. Quality of Life, depression, physical activity, parents, disability
\end{abstract}

Resumen. Este estudio examinó la calidad de vida (QoL) de los padres de niños discapacitados en Grecia. Además, se reporta la relación entre la calidad de vida y los síntomas depresivos y de la participación en actividades físicas. El total de la muestra estuvo constituida por 73 padres (edad promedio = 42.87 años, DE = 7.58), clasificadas en 42 padres de niños con discapacidad y 31 padres de niños sin discapacidad (grupo control). Los participantes respondieron el Inventario de Depresión de Beck II (BDI-II) (Beck, Steer \& Garbin, 1996), la escala QoL SF-36 v2 (Ware et al., 2007), y el Self Administered Physical Activity Checklist (SAPAC) (Sallis, Strikmiller, Harsha, \& Feldman, 1996). Las comparaciones multivariadas (lambda = .99, F $=.35, \mathrm{p}=.70$, eta $\left.^{2}=.01\right) \mathrm{y}$ univariadas entre los dos grupos de padres no mostró diferencias significativas en los componentes físicos (PCS) y mentales (MCS) de la escala SF-36. La QoL se relacionó significativamente con síntomas depresivos, mientras que la participación en actividades físicas no estuvo relacionada con la QoL. Por otra parte, los padres de los niños con discapacidad tuvieron menos comportamientos sedentarios comparados con los padres del grupo control. Los resultados generales se discuten en línea con los estudios pertinentes que examinan la calidad de vida de las familias con niños discapacitados.

Palabras claves. Calidad de vida, depresión, actividad Física, padres, discapacidad

\section{Introduction}

Quality of Life (QoL) may be perceived as a subjective sense of well-being and incorporates elements such as the physical and mental health, access to leisure time, education, sense of social belongingness, etc. (Kane, 2002). The term 'quality of life' may have a differentmeaning to different individuals (Kane, 2002), while for certain researchers it means almost everything beyond information about longevity death rates. According to the Encyclopedia of Public Health (2002), the QoL is an umbrella concept and includes the physical health, psychological and social well-being, socio economic status, relationships with family and friends, access to occupation, leisure, physical activity, etc. (Ware et al, 2007).

Researchers have examined the QoL of individuals with disabilities (Fellinger et al. 2005; Levasseur, Desrosiers \& Noreau, 2005; Schatz et al. 2005; Lavoie et al. 2005). Fellinger et al. (2005) examined the QoL and mental stress of 236 individuals with deafness. The researchers found that their sample had lower QoL compared to the 'general' population and concluded that health services may provide an effective mean of communication in order to increase the QoL of deaf individuals (Fellinger et al. 2005). Levasseur et al. (2005) examined older adults with physical disabilities (60 to 90 years old) and found that they exhibited a positive, although weak, association between social interaction and QoL (Levasseur et al. 2005). Schatz et al. (2005) studied asthma patients, 18 to 56 years old, and reported that their subjective perception of daily burden interfered with daily activities and overall QoL. Finally, Lavoie et al. (2005) examined the relationship among psychiatric status, levels of asthma control, and QoL in 406 adult asthma patients. The researchers suggested that the QoL was associated with several psychiatric disorders of asthmatic patients (Lavoie et al. 2005).

Fecha recepción: 30-09-14- Fecha envío revisores: 30-09-14- Fecha de aceptación: 15-11-14 Emmanouil K Skordilis eskord@phed.uoa.gr
Recently, researchers have examined the QoL of parents and siblings of individuals with disabilities (Salah Frih, Boudoukhane, Jellad, Salah, \& Rejeb, 2010; Davis \& Gavidia-Payne, 2009; Hatzmann et al., 2009; Lee et al., 2009; Davidson, 2001;). Salah Frih et al. (2010) examined parents living with their children $(\mathrm{N}=53)$ with cerebral palsy $(\mathrm{CP})$ and reported that both mothers (24.5\%) and fathers (11.6\%) exhibited high depressive scores. The researchers concluded that the psychological status of parents is negatively influenced from the presence of a child with CP at home (Salah Frih et al., 2010). Hatzmann et al., (2009) examined the QoL of parents with children experiencing metabolic diseases. The researchers found that the QoL was predicted from certain psychological variables to a wider extent compared to medical and socio-demographic variables (Hatzmann et al., 2009). Lee et al., (2009) compared the QoL of 89 parents with autism and 46 parents without disabilities. The researchers found lower QoL for the group of parents with autistic children, compared to the controls. Davis and GavidiaPayne (2009) examined the predictors of family QoL, in a group of families with children with disabilities. The researchers found that the parental perceptions and experiences of professional support were the predictors of QoL. Further, perceived intensity of problems and support from other family members were significant predictors of QoL as well (Davis \& Gavidia-Payne, 2009).

Further, certain factors associated with the QoL of parents living with children with disabilities have been reported as well. The most commonly reported are the socioeconomic status (Olsson \& Hwang, 2008), depression (Baily, Golden, Roberts \& Ford, 2007), family hardiness (Failla \& Corson Jones, 1991), psychological well-being (Eisenhower, Baker \& Blacher, 2005; Van Riper, Ryff \& Pridham, 1992), parental stress (Khamis, 2006), sleep quality (Chu \& Richdale, 2009), etc. Olsson and Hwang (2008) studied families of children with intellectual disabilities (ID) and stated that the presence of a child with intellectual disability (ID) does not predict poor maternal QoL. Instead, economic hardship and health were significant predictors of QoL (Olsson \& Hwang, 2008). Baily et al. (2007) found, in a systematic review that maternal stress and support were associated with the depressive 
symptoms experienced from mothers of children with developmental disabilities. Chu and Richdale (2009) examined 46 mothers and 50 children with developmental disabilities and found significant association between children's behavior problems and mother's sleep disturbances and depression. Eisenhower et al. (2005) examined the association between disability, behavior and well-being of mothers with autistic children. The researchers found that mothers reported higher parenting stress compared to controls, while severity of child syndrome contributed to maternal stress even after accounting for differences in behavior problems and cognitive level. Van Riper et al. (1992) examined the well-being of 34 families of children with Down syndrome and 41 controls. The researchers found no differences between the two groups and concluded that parenting a child with Down syndrome may be associated with adaptive functioning and resilience (Van Riper et al., 1992).

The acceptance of loss theory (Keany \& Glueckauf, 1999) and the cognitive adaptation theory of Taylor (1983) and Taylor, Lichtman and Wood (1984) guided the present study. According to Keany and Glueckauf (1999), the response to disability varies from complete denial to exaggeration and depends upon several environmental, biological, social and psychological factors. Keany and Glueckauf(1999) stated that four major changes must occur in order to successfully cope with the existing disability. These changes include: a) enlargement of values, b) subordination of physique relative to other values, c) containment of disability effects, and d) transformation of comparative to intrinsic values. On the other hand, the cognitive adaptation theory describes the general adjustment process of threatening events. Taylor and colleagues reported that this process incorporates three major cognitive steps: a) an attempt to give a meaning to a threatening event, b) an attempt to gain control over the threatening event, and c) an attempt to increase self-esteem. Marsh and Johnson (1999) stated that disability may be perceived as a catastrophic event, and reported the burden of disability to the family members. Marsh and Johnson (1999) described several burdens, classified either as subjective(e.g. sock, anxiety, guilt, disbelief, anger, despair, shame) and/ or objective (e.g. daily restrictions), along with the distress of family members due to the type and severity of the experienced disability (e.g. disturbances of mood, depression, self-destructive behavior, maladjusted behavior, poor daily living skills, etc).

Based on the above, the present study was designed shed more light in the topic and examine the QoL of parents living with their children with disability in Greece. More specifically, the association among the health related QoL with depression and involvement in physical activity were examined. Further, differences between parents of children with disabilities and controls were examined also. The independent variables were the parental status (parents with and parents without disabled children) and gender (male and female parents). The dependent variables were the health related QoL (physical and mental component), depressive symptoms and involvement in physical activity. Based on the daily burdens reported in the literature it was hypothesized that the Greek parents of disabled children would exhibit lower health related QoL, higher depressive symptoms and lower involvement in physical activity, compared to parents in the control group. Finally, a significant association among QoL, depressive symptoms and physical activity was anticipated for the group of parents with disabled children.

\section{Method}

\section{Participants}

The total sample incorporated seventy-three parents, divided to: a) forty-two parents having children with disabilities and b) thirty-one parents with non-disabled children (comparison group). A purposive sampling selection was used (Thomas \& Nelson, 1996) to recruit the parents in the first group from rehabilitation centers and special education settings in Athens, Greece. The parents in the control group were recruited from the same geographic areas in Athens.

\section{Measuring Instruments}

SF-36v2 (Quality of Life)

The SF-36v2 (Wareetal., 2007) is consisted from 36 items classified under the following eight dimensions: physical functioning, rolelimitation due to physical health problems, bodily pain, general health, vitality, social functioning, role limitation due to emotional health problems, and mental health. Scores range between 0 and 100, with a higher score indicating higher health-related quality of life. Further, the SF-36v2 incorporates the following scales: a) the Physical Component ScalePCS (physical functioning, physical role, bodily pain, and general health) and b) the Mental Component Scale-MCS (vitality, social functioning, emotional role, and mental health). The PCS and MCS were used for the purposes of the present study. The validity and reliability of the SF-36v2 in Greece has been reported by Pappa, Kontodimopoulos and Niakas (2005) and Anagnostopoulos, Niakas and Pappa (2005).

\section{Beck Depression Inventory II (BDI-II)}

The BDI-II was used to assess the depressive symptoms (Beck, Steer \& Garbin, 1996). It incorporates 21 items, reflecting the cognitive and affective - somatic elements of depression. Items are rated on a 4point Likert scale ( 0 to 3 ). Higher total scores are associated with more depressive symptoms. The BDI-II has been validated in Greece by Oikonomou and Psychountaki (2005), with a reported .92 Cronbach alpha coefficient.

\section{Self-Administered Physical Activity Checklist(SAPAC)}

Physical activity was measured with a checklist (SAPAC) (Sallis, Strikmiller, Harsha, \& Feldman, 1996), in daily minutes. The participants recalled time spent in 22 common daily physical activities and time spent in sedentary activities, such us playing video games, watching television, etc. The SAPAC examined the involvement in physical activity of both groups of parents (parents with disabled children and controls).

\section{Procedure}

The parents were contacted and a meeting was arranged for data collection. Before the assessment, the purpose of the study was explained and an informed consent was obtained. Parents responded to the three measuring instruments (SF 36v2, BDI-II, SAPAC) and a demographic questionnaire.

\section{Statistical Analysis}

The SPSS was used to analyze data (Norusis, 1993). The demographics were analyzed with frequencies, means and standard deviations. The Pearson coefficients examined the association among the dependent variables. Multivariate analysis (MANOVA) and post hoc independent t-test examined the differences between the parental groups. Univariate ANOVA was used when the multivariate findings exceeded significance $(\mathrm{p}<.05)$.

\section{Results}

The participants were mainly females $(\mathrm{N}=53)$, with a monthly income of 1001-2000 euros (45.2\%), while 46.6\% were senior high school graduates and $53.4 \%$ had an undergraduate University degree. With respect to the 42 parents with disabled children, 31 of their children were females and 10 males (Mean age $=11.86$ years, $\mathrm{SD}=$ 6.72), with different disabilities such as intellectual disability, autism, visual impairment, cerebral palsy, cancer, etc. Mean age of this group was 42.87 years old $(S D=7.58$ ), with a range from 24 to 70 years old.

Accordingly, the health related QoL, depressive symptoms and physical activity were assessed. With respect to the SF36v2 scores, both groups of parents exhibited higher PCS and lower MCS means compared to the Greek norms (Ware et al., 2007; Anagnostoploulos, Niakas \& Pappa, 2005). With respect to the BDI-II (Beck, Steer \& Brown, 1996), 2 parents exhibited severe depressive symptoms (2.7\%), 
3 parents experienced moderate (4.1\%), 13 parents experienced mild (18.8\%), while 54 parents experienced no depressive symptoms (74\%). The descriptive statistics are presented in tables 1 and 2.

\begin{tabular}{|c|c|c|c|}
\hline Variable & $\mathbf{M}$ & SD & $\mathbf{N}$ \\
\hline Parents with disabled children & & & 42 \\
\hline \multicolumn{4}{|l|}{ SF36v2 } \\
\hline PCS & 53.88 & 5.84 & 41 \\
\hline MCS & 44.92 & 10.71 & 41 \\
\hline \multicolumn{4}{|l|}{ SAPAC } \\
\hline Daily min. of Physical Activities & 53.38 & 75.95 & 40 \\
\hline $\begin{array}{l}\text { Daily min of Sedentary Behavior } \\
\text { BDI-II }\end{array}$ & 150.75 & 135.66 & 40 \\
\hline SomaticFactor & 7.00 & 3.62 & 40 \\
\hline Cognitive Factor & 3.03 & 3.35 & 40 \\
\hline Total BDI-II & 10.03 & 7.33 & 40 \\
\hline
\end{tabular}

Table 2 .

Descriptive Statistic: Control parents.

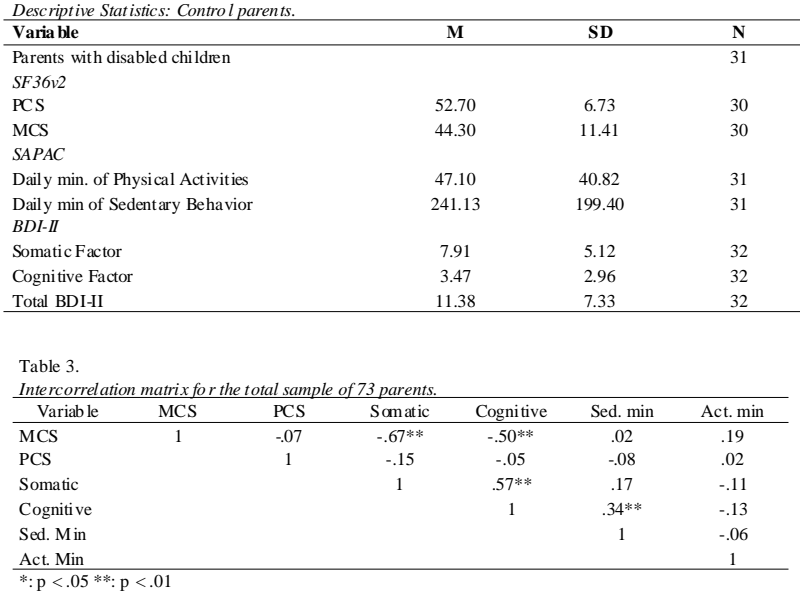

The intercorrelations among health related QoL, depression and physical activity were recorded afterwards. The intercorrelation matrix, for the total sample of 73 parents is presented in table 3.

Accordingly, the differences between parents with and without children with disabilities, with respect to their self-reported health related QoL (MCS and PCS), depressive symptoms and physical activity were examined. With respect to MCS and PCS elements of the SF36v2, no significant multivariate differences were found (lambda = $.99, \mathrm{~F}=.35, \mathrm{p}=.70$ eta $\left.^{2}=.01\right)$ (Figure 1$)$.

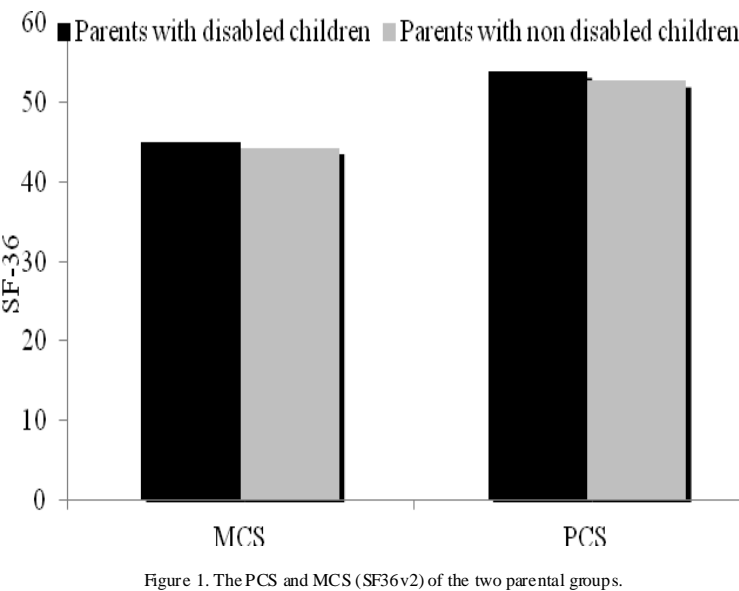

With respect to the BDI-II scores (cognitive and somatic factors), no significant multivariate differences were found between the two groups (lambda $=.99, \mathrm{~F}=.39, \mathrm{p}=.68$, eta $^{2}=.01$ ). The independent groups t-test, examining group differences in the total BDI-II score, was not significant too $(\mathrm{t}=-.85, \mathrm{p}=.44)$. The overall findings are presented in figure 2 .

Finally, we examined the differences between the two parental groups in the physical activity involvement. The multivariate results

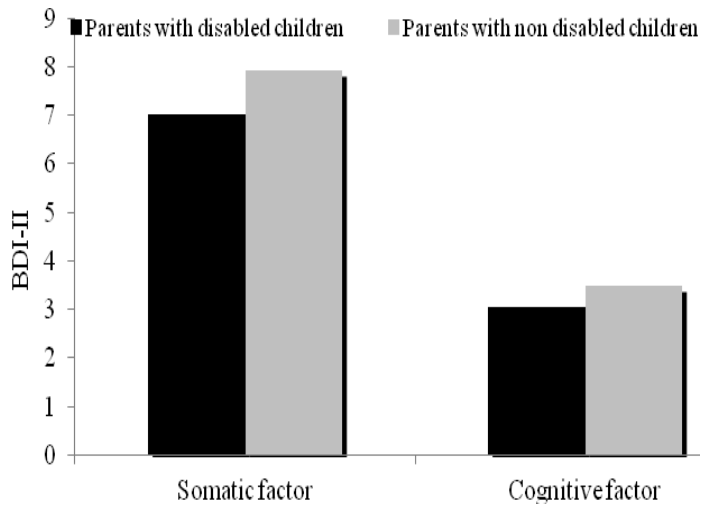

Figure 2. Comp arison between parental groups with respect to the Som atic and Cognitive BDI-II factors

were not significant (lambda $=.92, \mathrm{~F}=1.89, \mathrm{p}=.14$ eta $^{2}=.08$ ), but the univariate post hoc comparisons were significant for theminutes involved with sedentary activities $\left(\mathrm{F}=5.15, \mathrm{p}=.03\right.$, eta $\left.{ }^{2}=.07\right)$. Examination of the mean scores revealed that the parents with disabled children were involved less in daily sedentary activities $(\mathrm{M}=150.75 \mathrm{~min}, \mathrm{SD}=$ 135.66) compared to the control group of parents $(M=241.13 \mathrm{~min}, \mathrm{SD}$ $=199.40$ ). The overall findings are presented in figure 3 .

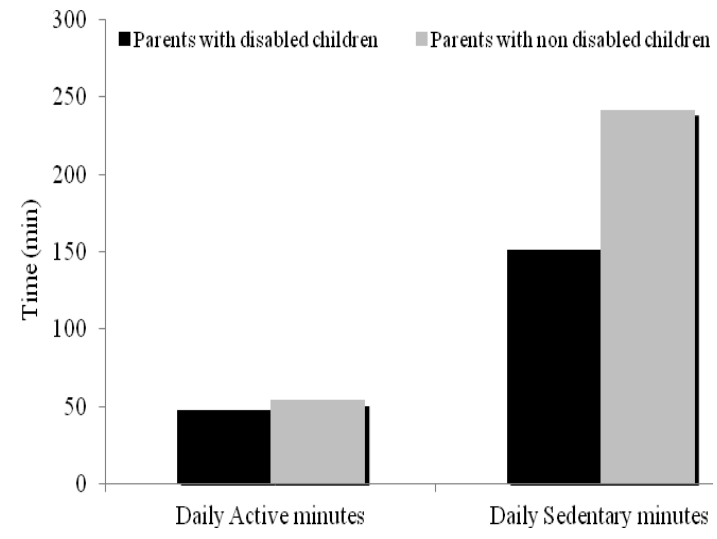

Figure 3. Daily investment (minutes) in active and sedentary activities for both groups of parents

\section{Discussion}

The study investigated the quality of life, depressive symptoms and involvement in physical activity, of Greek parents with and without disabled children.

Quality oflife

In the present study, the QoL did not differentiate parents with disabled children and controls. This finding is in line with Olsson and Hwang (2008) who reported that the presence of a child with intellectual disability did not predict poor maternal quality of life and general wellbeing (Olsson \& Hwang, 2008). This finding may be explained through the cognitive adaptation theory. Specifically, a person facing a threatening event usually: a) searches for a meaning and b) attempts to gain mastery and control the threatening situation (Singer et al., 1999). On the other hand, certain studies suggest that the QoL of parents who raise disabled children are lower compared to controls (Salah et al., 2010; Lee et al., 2009; Chu \& Richdale, 2009; Eisenhower et al., 2005). It seems therefore that this area remains open for future researchers in the field.

Quality of Life and Depression

No differences were evident between the parental groups with respect to depressive symptoms. Similarly, Van Riper, Ryff and Pridham (1992) did not report differences regarding several variables, such as depression, autonomy, purpose in life, positive relations, environmental mastery, self-acceptance and personal growth of parents who have 
disabled children. Further, only $2.7 \%$ of the parents exhibited severe depressive symptoms. This finding is in line with Salah et al. (2010) who reported that $25 \%$ of mothers and $11 \%$ of fathers exhibited high depressive risk, related to their social and financial embarrassment. On the other hand, other researchers have reported increased anxiety, depressive symptoms and lower maternal QoL due to the presence of disabled children (Bumin, Günal \& Tükel, 2008; Altindag, et al. 2007). The only differences in the present study were found in the total BDIII score. The intercorrelations however revealed that the MCS of QoL was negatively associated with the BDI-II subscales, suggesting that the higher quality of life is associated with lower depressive symptoms.

Involvement in Physical Activity

No differences were evident between the two groups of parents (those with and without children with disabilities). Interestingly, significant differences were evident with respect to sedentary behavior. Parents with disabled children were less sedentary and more energetic compared to their counterparts. An explanation may be that they have less time to invest to sedentary activities due to the daily responsibilities they face to raise their children. Further, the major part of the sample was recruited from rehabilitation centers in Athens and probably they were already aware for the detrimental effects of sedentary behavior and the importance of daily physical activity.

The present hypothesis, with respect to the association between QoL and involvement to physical activity was not confirmed. It will be useful to reexamine this finding, possibly with a wider sample, since others studies have reported significant association between habitual physical activity with mental health, QoL and low depressive symptoms (Salmon, 2001; De Moor, Beem, Stubbe, Boomsma \& De Geus, 2006).

Certain limitations do not allow the generalization of the present findings without caution. First, the sample was not randomly selected. Instead, it was recruited, with a purposive sampling method from certain rehabilitation centers and special education settings in the wider area of Athens, Greece. Second, the parents with disabled children constituted a heterogeneous group, with respect to their children's disability. Third, only self-reported questionnaires were used to assess QoL, depressive symptoms and physical activity. It may only be assumed therefore that all parents responded in a good faith.

The present study is a continuation of previous examining the impact of having a child with disability to the QoL of family members. The QoL was associated with depressive symptoms, and parents of disabled children exhibited less sedentary behaviors compared to their counterpart parents of children without disabilities. Professionals working with parents raising disabled children may consider promoting alternative strategies, including physical activity to enhance their overall quality of life.

\section{References}

Altindag, O., Iskan, A., Akcan, S., Koksal, S., Ercin, M., \&Ege, L. (2007). Anxiety and depression levels in mothers of children with cerebral palsy. Turkish Journal Physical Medicine and Rehabilitation, 53, 22-24.

Anagnostopoulos, F., Niakas, D., \& Pappa, E. (2005). Construct validation of the Greek SF-36 Health Survey. Quality of Life Research, 14, 1959-1965.

Bailey, B., D., Golden, N., R., Roberts, J. \& Ford, A. (2007). Maternal depression and developmental disability: Research critique. Mental Retardation and Developmental Disabilities Research Reviews, 13, 321-329.

Beck, A. T., Steer, R. A., \& Garbin, M. G. (1996). Beck Depression Inventory Manual ( $2^{\text {nd }}$ ed.). San Antonio, TX: Psychological Corporation.

Bumin, G., Günal, A., \& Tükel, S. (2008). Anxiety, depression and quality of Life in mothers of disabled children. S.D.U. Tip Fakültesi Dergisi, 15(1) 6-11.

Chu, J., \& Richdale, A. (2009). Sleep quality and psychological wellbeing in mothers of children with developmental disabilities. Research in Developmental Disabilities, 30, 1512-1522.

Davidson, A. (2001). Parental features and quality of life in the decision to remove children at risk from home. Child Abuse \& Neglect, 25, 47-64.

Davis, K., Gavidia-Payne, S. (2009). The impact of child, family, and professional support characteristics on the quality of life in families of young children with disabilities. Journal of Intellectual \& Developmental Disability, 34(2), 153162.
De Moor, M. H., Beem, A. L., Stubbe, J. H., Boomsma, D. I., \& De Geus, E. J. (2006). Regular exercise, anxiety, depression and personality: a populationbased study. Preventive Medicine, 42(4), 273-279.

Eisenhower, A.S., Baker, B.L., \& Blacher, J. (2005). Preschool children with intellectual disability: syndrome specificity, behaviour problems, and maternal well-being. Journal of Intellectual Disability Research, 49(9), 657-671.

Failla S. \& Corson Jones L. (1991). Families of children with developmental disabilities: An examination of family hardiness. Research in Nursing \& Health, 14, 41-50.

Fellinger, J., Holzinger, D., Dodner, U., Gerich, J., Lehner R., Lenz, G., \& Goldberg, D. (2005). Mental distress and quality of life in a deaf population. Social Psychiatric Epidemiology, 40, 737-742.

Hatzmann, J. Valstar, M., Bosch, A., Wijburg, F., Heymans, H., \& Grootenhuis, M. (2009). Predicting health-related quality of life of parents of children with inherited metabolic diseases. Acta Pediatrista, 1205-1210.

Keany, K., \& Glueckauf, R. (1999). Disability and value change: an overview and reanalysis of acceptance of loss theory. In: The Psychological and Social Impact of Disability (Marinelli, R., \& Dell Orto, A). New York, NY: Springer Publishing Company.

Kane, R. A. (2002). «Quality of Life.» Encyclopedia of Public Health. Retrieved September 04, 2011 from Encyclopedia.com: http://www.encyclopedia.com/ doc/1G2-3404000706.html

Khamis, V. (2006). Psychological distress among parents of children with mental retardation in the United Arab Emirates. Social Medicine, 64, 850-857.

Lavoie, K., Cartier, A., Labrecque, M., Bacon, S., Lamiere, C., Malo, J.L., Lacoste, G., Barone, S., Verrier, P., \& Ditto, B. (2005). Are psychiatric disorders associated with worse asthma control and quality of life in asthma patients? Respiratory Medicine, 99, 1249-1257.

Lee, K. G., Lopata, C., Volker, M. A., Thomeer, M. L., Nida, R. E., Toomey, J. A., Chow, S. Y., \& Smerbeck, A., M. (2009). Health-related quality of life of parents of children with high-functioning autism spectrum disorders. Focus on Autism and Other Developmental Disabilities, 24(4), 227-239.

Levasseur, M., Desrosiers, J., \& Noreau, L. (2005). Is social participation associated with quality of life of older adults with physical disabilities? Disability and Rehabilitation, 26, 1206-1213.

Marinelli, P., Dell Orto, A., E. (1999). The Psychological and Social Impact of Disability, (4th edition). New York, NY: Springer Publishing Company.

Marsh, D., \& Johnson, D. (1999). The family experience of mental illness: Implications for intervention. In: The Psychological and Social Impact of Disability (Marinelli, R., \& Dell Orto, A). New York, NY: Springer Publishing Company.

Norusis, M.J. (1993). SPSS for Windows: professional statistics, Release 6.0. Chicago, IL: SPSS.

Oikonomou, A., \& Psychountaki, M. (2005). Đñióáñiiiãp ôĩõ Åñùôçiáôïeiiãßïõ Êáô̈Uèëéøçò ôiõ Beck óå åëęçíêeü đëçèõóiü. [Adaptation of the Beck Depression Inventory II (BDI-II) in Greek]. Unpublished manuscript, Department of Physical Education and Sport Science, University of Athens.

Olsson, M. B., \& Hwang, C. P. (2008). Socioeconomic and psychological variables as risk and protective factors for parental well-being in families of children with intellectual disabilities. Journal of Intellectual Disability, 12, 1102-1113.

Pappa, E., Kontodimopoulos, N., \& Niakas D. (2005). Validating and norming of the Greek SF-36 Health Survey. Quality of Life Research, 14, 1433-1438.

Salah, Z., Boudoukhane, S., Jellad, A., Salah, S. \& Rejeb, N. (2010). Quality of life of children with cerebral palsy. Quality of Life Research, 30(1), 18-24.

Sallis, J.F., Strikmiller, P.K., Harsha, D., \& Feldman, H.A. (1996). Validation of interviewer and self-administered physical activity checklists for fifth grade students. Medicine and Science in Sports \& Exercise, 28, 840-851.

Salmon, P. (2001). Effects of physical exercise on anxiety, depression, and sensitivity to stress: A unifying theory. Clinical Psychology Review, 21(1), 33-61.

Schatz, M., Mosen, D., Apter, A., Zeiger, R., Vollmer, W., Stibolt, T., Leong, A., Johnson, M., Mendosa, G., \& Cook, F. (2005). Relationships among quality of life, severity and control measures in asthma: An evaluation using factor analysis. The Journal of Allergy and Clinical Immunology, 115(5), 1049 1055.

Singer, G. H. S., Marquis, J., Powers, L. K., Blanchard, L., Divenere, N., Santelli, B., Ainbinder, J. G., \& Sharp, M. (1999). A multi-site evaluation of parent to parent programs for parents of children with disabilities. Journal of Early Intervention, 22(3), 217-229.

Taylor, S. E. (1983). Adjustment to threatening events: A theory of cognitive adaptation. American Psychologist, 38, 1161-1173.

Taylor, S. E., Lichtman, R. R., \& Wood, J. V. (1984). Attributions, beliefs about control, and adjustment to breast cancer. Journal of Personality and Social Psychology, 46(3), 489-502.

Thomas, J. R., \& Nelson, J. K. (1996). Research Method in Physical Activity (2nd Ed.). Champaign, IL: Human Kinetics.

Van Riper, M., Ryff, C., \& Pridham, K. (1992). Parental family well-being in families of children with Down syndrome: A comparative study. Research in Nursing \& Health, 15, 227-235.

Ware, J. E., Kolinski, M., Bjorner, J. B., Turner-Bowker, D. M., Gandek, B., \& Maruish, M. E. (2007). User's manual for the SF-36v $2^{\circledR}$ Health Survey $\left(2^{\text {nd }}\right.$ Ed.). Lincoln, RI: Quality Metric Incorporated. 